\title{
From studying chemistry to publishing chemistry
}

\author{
Matteo Cavalleri ${ }^{1}$ \\ ${ }^{1}$ Affiliation not available
}

May 18, 2021

\begin{abstract}
Science in Action Seminar Series at Skyline College, May 11, 2021

Matteo (@physicsteo on Twitter) studied Chemistry at the University of Milan (Italy) and University of Valencia (Spain) before obtaining his Ph.D. in the Quantum Chemistry group of the Physics Department at Stockholm University (Sweden). After 3 years' experience as a researcher in Berlin (Germany), working on computer simulations of novel catalytic materials, he left the lab bench (which was actually a computer) to join the US-based STEM publisher Wiley in 2010. Matteo held several editorial roles in various scholarly journals in chemistry and material sciences prior to becoming the publisher of the material sciences and physics group at Wiley, overseeing the operations of the US-based journals in those areas.
\end{abstract}

Rich media available at https://speakerdeck.com/teowaits/from-studying-chemistry-topublishing-chemistry

Rich media available at https://www . youtube.com/watch?v=0KP4c0SSa2o
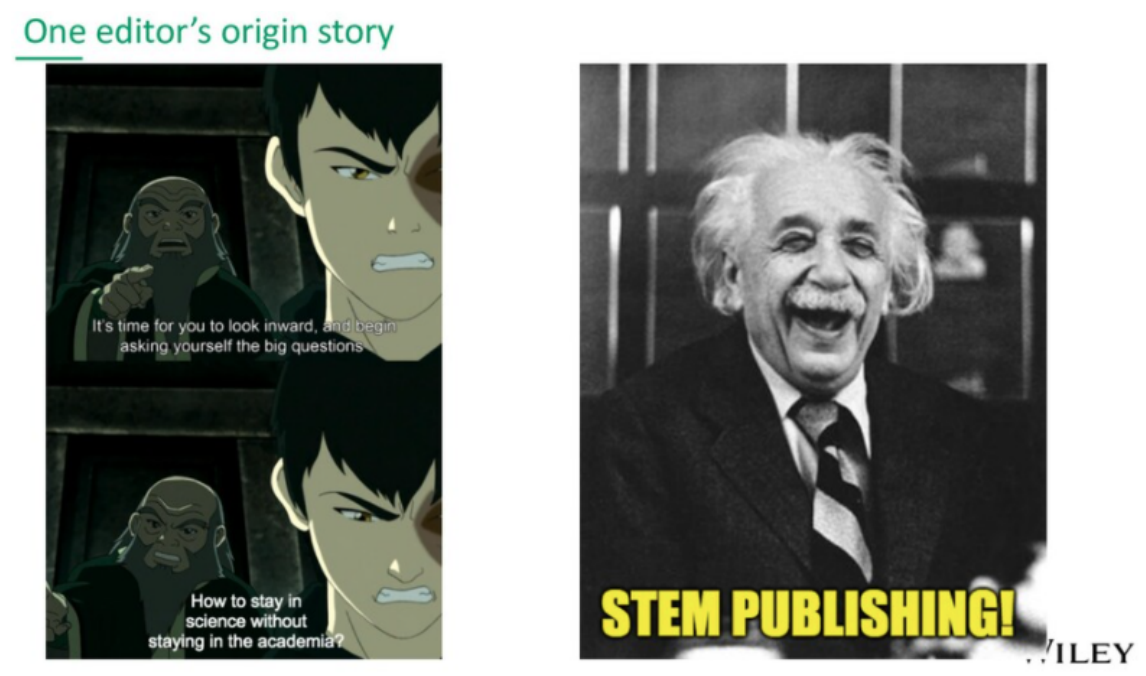

Figure 1: Meme:d it or it didn't happened 